\title{
CHARACTERIZING THE LANDSAT GLOBAL LONG-TERM DATA RECORD
}

\author{
T. Arvidson ${ }^{a}$ *, S. N. Goward ${ }^{b}$, D. L. Williams ${ }^{c}$ \\ a Lockheed Martin, Goddard Space Flight Center, Code 614.4, Greenbelt, MD, 20771 - terry.arvidson@gsfc.nasa.gov \\ ${ }^{b}$ Department of Geography, University of Maryland, 2181 LeFrak Hall, College Park, MD, 20782 - \\ sgoward@umd.edu \\ ${ }^{c}$ NASA/ Goddard Space Flight Center Code 614, Greenbelt, MD, 20771 -darrel.l.williams@nasa.gov
}

KEY WORDS: Landsat, Metadata, Archiving, Global, Standards, International, Format

\begin{abstract}
:
The effects of global climate change are fast becoming politically, sociologically, and personally important: increasing storm frequency and intensity, lengthening cycles of drought and flood, expanding desertification and soil salinization. A vital asset in the analysis of climate change on a global basis is the 34-year record of Landsat imagery. In recognition of its increasing importance, a detailed analysis of the Landsat observation coverage within the US archive was commissioned. Results to date indicate some unexpected gaps in the US-held archive. Fortunately, throughout the Landsat program, data have been downlinked routinely to International Cooperator (IC) ground stations for archival, processing, and distribution. These IC data could be combined with the current US holdings to build a nearly global, annual observation record over this 34 -year period. Today, we have inadequate information as to which scenes are available from which IC archives. Our best estimate is that there are over four million digital scenes in the IC archives, compared with the nearly two million scenes held in the US archive. This vast pool of Landsat observations needs to be accurately documented, via metadata, to determine the existence of complementary scenes and to characterize the potential scope of the global Landsat observation record. Of course, knowing the extent and completeness of the data record is but the first step. It will be necessary to assure that the data record is easy to use, internally consistent in terms of calibration and data format, and fully accessible in order to fully realize its potential.
\end{abstract}

\section{INTRODUCTION}

Global climate change is rapidly becoming a common discussion point in the general populace, a rising concern for the scientific community, and a priority for policy and decision makers. Studies of the impact of climate change are conducted at many levels-global, regional, and local. Remotely sensed data at a moderate resolution-from 10 to 119 meters (Green, 2006)-play a critical role in addressing these concerns. As the only systematic global archive of land scenes at a moderate resolution of 30 meters, the Landsat archive is key to the study of the changes being recognized in our global climate system.

Landsat has primarily been managed as a survey mission, concentrating on achieving global coverage at least annually. Thus a considerable archive of data has been gathered for the purpose of being available if needed in the future, as opposed to being acquired in response to a specific request. The exception to this is a period of commercialization ushered in by the Land Remote Sensing Commercialization Act of 1984 (Public Law 98-365) and ended by the 1992 Land Remote Sensing Policy Act (Public Law 102-555) (Green, 2006). The commercial operator, EOSAT (later Space Imaging), concentrated on acquisitions based on user requests, data for which they had a buyer.

Additionally, Landsat data characteristics and calibration are generally well understood, enabling the goal of continuity from one spacecraft and sensor to the next.

The first Landsat satellite was launched in 1972 and there has been continuous Landsat presence in orbit since then. Landsat 5 and Landsat 7 are currently operational, respectively adding a total of 6,000 and 9,000 scenes per month to the U.S. archive.
Given the importance of the 34-year Landsat archive to the science community, the National Satellite Land Remote Sensing Data Archive (NSLRSDA) Advisory Committee commissioned an analysis of the state of the US Landsat holdings. This paper reports on the results-to-date of that analysis.

\section{US ARCHIVE STATUS}

Since 1972, we have been accumulating Multispectral Scanner (MSS, from Landsats 1-5), Thematic Mapper (TM, from Landsats 4-5), and Enhanced Thematic Miapper Plus (ETM+, from Landsat 7) data in the US archive (Table 1). The archive is housed at the US Geological Survey's Center for Earth Observation and Science (EROS) in Sioux Falls, South Dakota.

\begin{tabular}{|l|l|r|}
\hline Date Range & Sensor Source & \# of scenes \\
\hline $1972-1992$ & Multispectral Scanner & 649,477 \\
\hline $1982-$ present & Thematic Mapper & 643,977 \\
\hline $1999-$ present & $\begin{array}{l}\text { Enhanced Thematic } \\
\text { Mapper Plus }\end{array}$ & 605,098 \\
\hline TOTAL & & $\mathbf{1 , 8 9 8 , 5 5 2}$ \\
\hline
\end{tabular}

Table 1. US archive holdings by sensor (as of March 2006).

EROS personnel are constantly assessing the physical state of the archive, refreshing the archive media, and recovering data from deteriorating media. For example, another 20,000 TM scenes were recently identified during a transcription of tapes sent to the EROS by EOSAT.

\footnotetext{
* Corresponding author.
} 
In response to the NSLRSDA commission, we used metadata generated during the archival process to produce graphic representations of the annual and seasonal coverage for each Landsat sensor type in the archive. An example of each is shown in Figures 1-5. You can examine the full set of coverage graphics in detail at the following URL: http://edc.usgs.gov/archive/nslrsda/geoCov.html.

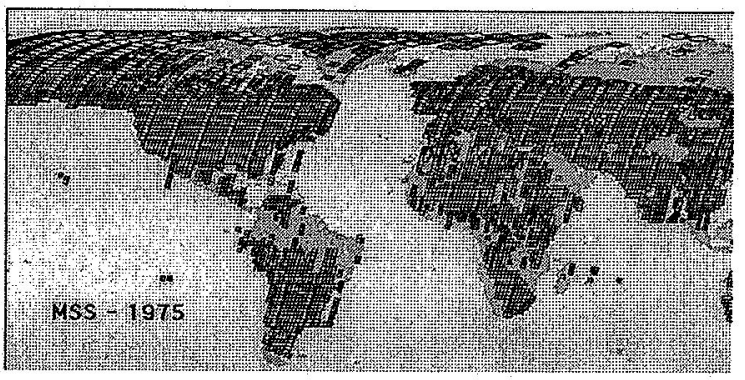

Figure 1. MSS 1975 annual coverage in US archive. Red represents images that are "unusable", with $<5$ quality rating and $>30 \%$ cloud cover. Yellow represents images having $\geq 5$ quality rating and cloud cover $\leq 30 \%$

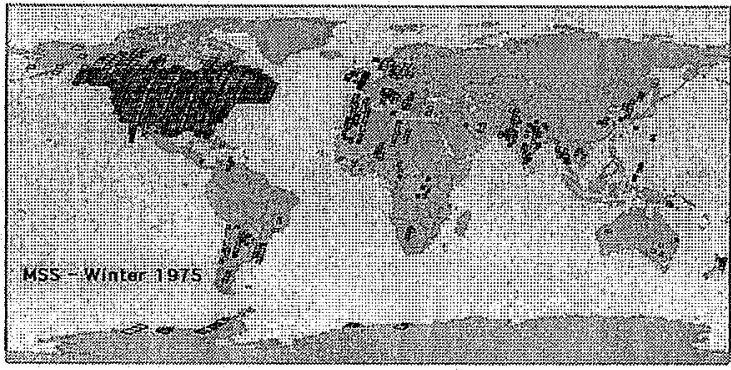

Figure 2. MSS Dec. 1974 - Feb. 1975 winter season. Red represents images that are "unusable", with $<5$ quality rating and $>30 \%$ cloud cover. Yellow represents images having $\geq 5$ quality rating and cloud cover $\leq 30 \%$.

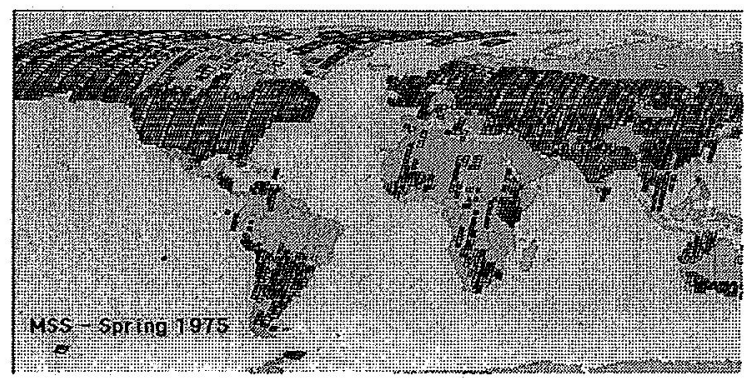

Figure 3. MSS Mar. - May 1975 spring season. Red represents images that are "unusable", with $<5$ quality rating and $>30 \%$ cloud cover. Yellow represents images having $\geq 5$ quality rating and cloud cover $\leq 30 \%$

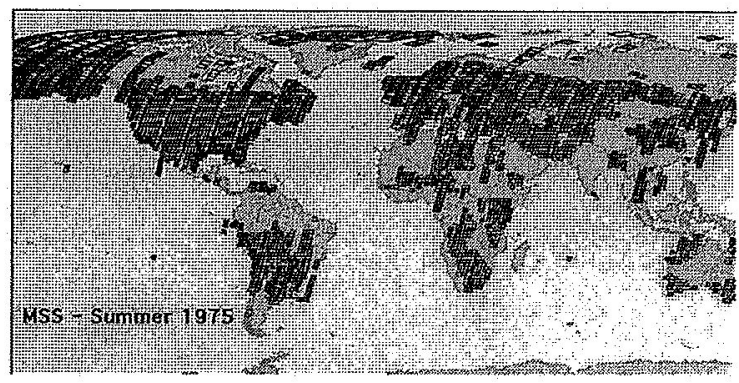

Figure 4. MSS June - Aug. 1975 summer season. Red represents images that are "unusable", with $<5$ quality rating and $>30 \%$ cloud cover. Yellow represents images having $\geq 5$ quality rating and cloud cover $\leq 30 \%$

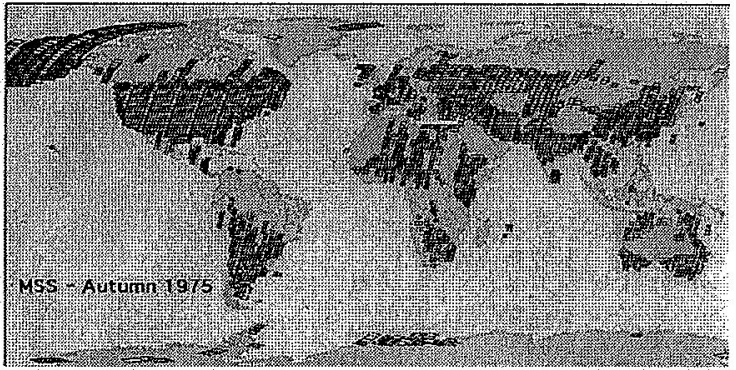

Figure 5. MSS Sept. - Nov. 1975 autumn season. Red represents images that are "unusable", with <5 quality rating and $>30 \%$ cloud cover. Yellow represents images having $\geq 5$ quality rating and cloud cover $\leq 30 \%$

Our subsequent analysis of the annual maps revealed surprises. The global coverage was neither as consistent nor complete as we expected. We went through historical documentation and interviewed Landsat personnel to discover why this was so. Table 2 summarizes the reasons we found for coverage gaps. Further details can be found in Goward et al., 2006. Having discovered the extent of the gaps, our next concern is identifying data that might fill these gaps -perhaps from the international archiveș.

\begin{tabular}{|l|l|}
\hline CATEGORY & EXAMPLES \\
\hline Program management & - Commercialization period \\
\hline Spacecraft problems & $\begin{array}{l}\text { - Ku-band failures on 4 and 5 } \\
\text { - Power problems on 4 } \\
\text { - Recorder problems on 1-3 }\end{array}$ \\
\hline $\begin{array}{l}\text { Sensor problems } \\
\text { - SSS line start problems on 1-3 }\end{array}$ \\
\hline $\begin{array}{l}\text { Communication } \\
\text { constraints }\end{array}$ & - Late launch of TDRS-West \\
\hline Acquisition priorities & - Reef campaign in 1981-82 \\
\hline
\end{tabular}

Table 2. Reasons for gaps in the US archive global coverage.

\section{INTERNATIONAL ARCHIVE STATUS}

From the onset of the Landsat program, participation of ground stations sponsored by other countries has been an important part of the mission, enhancing the global nature of the Landsat archive. This network of International Cooperator (IC) stations has been active since 1972, some since the beginning, others off 
and on, some for short campaign periods only. The current complement of US and IC stations is shown in Figure 6.

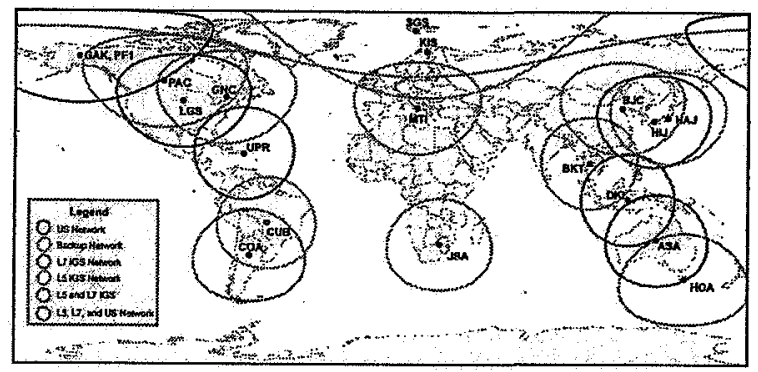

Figure 6. Current network of Landsat stations.

The IC stations are operated under a Memorandum of Understanding between the IC Government agency and the US operating agency for Landsat; some ICs comprise more than one station. The ICs are responsible for acquisition, archive, product generation, and distribution of the Landsat data that is downlinked to their stations. Each IC station receives a direct downlink of the land scenes within its acquisition circle, every viewing opportunity. Thus there is a deep archive at each IC station from which gaps in the US holdings over their geographical areas could be filled. The caveats placed on the ICs include adherence to the Landsat data policies and retention of the Landsat data in an archive. If they make the decision to retire the archive, they must give the US first refusal on incorporating the IC archive holdings into the US archive.

Today, each IC must return metadata to the US detailing data entered into their archive. In the past, this was not a consistently-applied policy nor was there consistent willingness on the part of the ICs to submit the metadata. Therefore, we do not have a clear picture as to what data are in the IC archives around the world. Based on the metadata that has been submitted over the years, we can estimate that there are two to three times more data in the IC archives than we have in the US archive (see Table 3). We have started efforts to remedy this lack of knowledge of the IC holdings.

\begin{tabular}{|l|l|r|}
\hline Countries Involved & $\begin{array}{l}\text { Years } \\
\text { Active }\end{array}$ & $\begin{array}{l}\text { Holdings } \\
\text { (Scenes) }\end{array}$ \\
\hline $\begin{array}{l}\text { Australia, Brazil, Canada, China, } \\
\text { Europe, Indonesia, Japan, South } \\
\text { Africa, Thailand }\end{array}$ & $\geq 20$ & $4,023,180$ \\
\hline $\begin{array}{l}\text { Argentina, Ecuador, India, Pakistan, } \\
\text { Saudi Arabia, South Korea, Taiwan }\end{array}$ & $<20$ & 223,284 \\
\hline $\begin{array}{l}\text { Antarctica, Dubai, Gabon, Iran, } \\
\text { Kenya, Kyrgyzstan, Mongolia }\end{array}$ & $\begin{array}{l}\text { Short- } \\
\text { term }\end{array}$ & 7,085 \\
\hline $\mathbf{2 3}$ countries, 30 stations & & $\mathbf{4 , 2 5 3 , 5 4 9}$ \\
\hline
\end{tabular}

Table 3. Scenes held at IC archives.

\section{ACHIEVING A GLOBAL ARCHIVE}

We have identified several steps toward achieving a more complete global Landsat archive that is useful and supportive of global climate change studies. These efforts are concentrating on the identification of IC holdings, establishing the status (or "state of health") of the archived data, enabling access to the data through the implementation of standards, and enhancing utility of the data through improved calibration.

\subsection{Metadata}

The USGS and ICs have agreed to establish a consistent metadata definition for Landsats 1-7, for all three sensors. This effort is in the final stages of review. Once established, the ICs will submit to EROS metadata for the full set of Landsat holdings in their archives. This will be a gradual process in some cases, where older MSS data sets have yet to be incorporated into an online digital archive system. The US will ingest the metadata and establish a more complete global catalog of Landsat holdings.

\subsection{Archive Maintenance}

Maintaining an archive of digital data requires constant attention, and hence constant financial support. Data on older media need to be transcribed onto newer media. As time passes, this becomes more difficult to accomplish for data sets still residing on wideband video tapes. Deterioration of the tape itself and scarcity of tape drives with which to read the tapes compound the problems. It is vital that we assure that archives are being maintained and media is being refreshed.

\subsection{Access Standards}

Online catalog data and browse images ensure archive accessibility to researchers. For Landsat 7 , an exchange product standard has been established and has proven its worth when data exchange has been necessary among the stations. Extending this standard to Landsat 5, and subsequently to Landsats 1-4 should be the next step. An important part of the exchange product standard is the validation of the format generated by each station to assure compliance with the standard.

\subsection{Data Utility}

Once we have identified the global archive extent and enabled archive maintenance and data exchange, we need to address data utility. Calibration of the Landsat 7 data set is excellent (Markham et al., 2004) and efforts are underway to improve the calibration of Landsat $5 \mathrm{TM}$ through cross-calibration with Landsat 7 ETM+ (Teillet et al., 2001). We have yet to fully address the calibration of the MSS. There are known artifacts and problems, and very little documentatiou on the calibration history of the sensor.

\section{CONCLUSIONS}

Our analysis of the US-held Landsat archive has highlighted the importance of the IC-held assets in forming a more robust global Landsat archive with minimal coverage gaps. A standardized metadata format is essential to building a catalog of the Landsat archives held at IC stations.

We must concern ourselves with the deterioration of the global Landsat archive. Financial and technical support must be found within the Landsat stations, including that of the US, to maintain, document, and rescue, as necessary, the Landsat archives around the world.

Identifying and stabilizing the archives should be followed by enhancing the usability of the entire scope of archives, so that researchers can work as seamlessly as possible using Landsat 1 MSS through Landsat 7 ETM+ data. This includes calibration of the data sets to maximize radiometric consistency, devising corrections for known image artifacts and sensor effects, 
generation of orthorectified best-available global snapshots at regular intervals of 2-3 years, and continual updating of this calibration as we learn more about the older data sets.

Knowing the extent and completeness of the data record is but the first step. Assuring that the data record is easy to use, internally consistent in terms of calibration and data format, and fully accessible is the ultimate requirement to arrive at a truly global and productive Landsat archive.

\section{REFERENCES}

Goward, S.N., T.J. Arvidson, J. Faundeen, D.L. Williams, J. Irons, and S. Franks, 2006. Historical record of Landsat global coverage: Mission operations, NSLRSDA, and international cooperator stations, Photogrammetric Engineering \& Remote Sensing, 72(10).

Green, K., 2006. Landsat in context: The land remote sensing business model, Photogrammetric Engineering \& Remote Sensing, 72(10).

Markham, B. L., Thome, K.J., Barsi, J.A., Kaita, E., Helder, D.L., Barker, J.L., and Scaramuzza, P. 2004. Landsat-7 ETM+ On-orbit reflective-band radiometric stability and absolute calibration. IEEE TRANSACTIONS ON GEOSCIENCE AND REMOTE SENSING 42 (12): 2810-2820.

Public Law 98-365, 1984. Land Remote Sensing Commercialization Act of 1984 . July 17, 1984.

Public Law 102-555, 1992. 1992 Land Remote Sensing Policy Act. October 28, 1992.

Teillet, P.M., J.L. Barker, B.L. Markham, R.R. Irish, G. Fedosejevs, and J.C. Storey, 2001. Radiometric crosscalibration of Landsat 5 Thematic Mapper and Landsat-7 Enhanced Thematic Mapper Plus based on tandem data sets, Remote Sensing of Environment, 78(1-2):39-54. 